\title{
CLÁUSULAS RELATIVAS \\ NA FALA \\ ESPONTÂNEA: \\ UMA DEFINIÇÃO \\ BASEADA NA TEORIA \\ DA LÍNGUA \\ EM ATO
}

\author{
ORACIONES DE RELATIVO EN EL HABLA ESPONTÁNEA: \\ UNA DEFINICIÓN BASADA EN LA TEORÍA DE LA LENGUA EN ACTO
}

RELATIVE CLAUSES IN SPONTANEOUS SPEECH:

A DEFINITION BASED ON THE LANGUAGE INTO ACT THEORY

Crysna Bonjardim da Silva Carmo*

Universidade Federal de Minas Gerais

Universidade do Estado da Bahia

\begin{abstract}
RESUMO: Este artigo apresenta uma definição de cláusula relativa para a fala espontânea do português brasileiro baseada na Teoria da Língua em Ato (CRESTI, 2000). Essa teoria postula o enunciado como a unidade de referência da fala, ou seja, como a menor unidade linguística pragmaticamente autônoma (ato de fala). Nesse quadro, as relações de dependência estabelecidas pela sintaxe podem ser alteradas pela estrutura informacional da prosódia, ou por outra, a sintaxe está restringida aos limites das unidades informacionais delimitadas pela prosódia, configurando-se em ilhas sintático-semânticas. Para realizar este estudo, utilizou-se um corpus de fala espontânea, o C-ORAL BRASIL (RASO; MELLO, 2002). A partir da definição de relativa postulada neste estudo, chegou-se aos seguintes resultados acerca dessas cláusulas: (i) apresentam a semântica de restrição de um conjunto denotado dentro de um conjunto de referência subjacente; (ii) ocorrem linearizadas dentro do enunciado simples ou complexo; (iii) ocorrem isoladas ou como componentes de sentenças dentro dos enunciados.

PALAVRAS-CHAVE: Fala espontânea. Cláusulas relativas. Teoria da Língua em Ato. Linguística de Corpus.
\end{abstract}

RESUMEN: Este estudio presenta una definición de la oración de relativo para el habla espontánea del portugués brasileño basada en la Teoría de la Lengua en Acto (CRESTI, 2000). Esta teoría postula el enunciado como la unidad de referencia del habla, o sea,

\footnotetext{
* Mestra em Linguística pela Universidade Federal de Juiz de Fora (UFJF). Doutoranda pelo Programa de Pós-Graduaça em Estudos Linguísticos Universidade Federal de Minas Gerais (UFMG). Professora Assistente B da Universidade do EstadodaBahia (UNEB).E-mail:crysnabonjardimsc@gmail.com.
} 
como la menor unidad lingüística pragmáticamente autónoma (acto de habla). En este enfoque, las relaciones de dependencia establecidas por la sintaxis pueden ser modificadas por la estructura informacional de la prosodia, o sea, la sintaxis está restringida a los límites de las unidades de información delimitadas por la prosodia, configurándose en islas sintáctico-semánticas. Para realizar este estudio, fue utilizado un corpus de habla espontánea, el C-ORAL-BRASIL (RASO; MELLO, 2012). Partiéndose de la definición postulada este estudio, se llegó a las siguientes conclusiones sobre esas oraciones: (i) presentan la semántica de restrición de un conjunto denotado dentro de un conjunto de referencia subyacente; (ii) ocurren de forma lineal dentro del enunciado simple o complejo; (iii) ocurren aisladas o como componentes de oraciones dentro de los enunciados.

PALABRAS CLAVE: Habla espontánea. Oraciones de relativo. Teoría de la Lengua en Acto. Lingüística de Corpus.

ABSTRACT: This paper presents a definition of the relative clause for Brazilian Portuguese spontaneous speech based on the Theory of Language in Act (CRESTI, 2000). This theory designates the utterance as the reference unit to speech, that is, the smallest pragmatically autonomous linguistic unit (the speech act). In this framework, the dependency relations established by the syntax can be changed by the informational structure of the prosody, that is: the syntax is restricted to the limits of the informational units as read by prosody, thus forming syntactic/semantic islands. This study made use of the C-ORAL BRASIL spontaneous speech corpus (RASO; MELLO, 2012). Based on the definition proposed in this study, the following statements can be made about relative clauses: (i) they show the constraint semantics of a denoted set within an underlying reference set; (ii) they appear linearized within a simple or complex utterance; (iii) they occur in isolation or as sentence components within utterances.

KEYWORDS: Spontaneous speech. Relative clauses. Theory of Language in Act. Corpus Linguistics.

\section{INTRODUÇ̃̃O}

As investigações sobre cláusulas relativas continuam em aberto na agenda linguística, sobretudo no campo da fala espontânea, uma vez que os estudos tradicionais ainda privilegiam a língua escrita. Mesmo aqueles estudos voltados para os dados de fala adotam transcrições em suas pesquisas que, a rigor, são dados escritos, pois não consideram a influência do comportamento da prosódia na segmentação da fala. É claro que, antes do século XX, não havia tecnologia que permitisse esse tipo de investigação, já que para o exame da fala é fundamental a observação simultânea de texto-som, metodologia viabilizada pelo desenvolvimento do computador e da Linguística de Corpus. Além disso, o próprio conceito de cláusula relativa está ainda em debate, tendo em vista que as definições tradicionais disponíveis não contemplam a natureza da fala espontânea e são imprecisas no que se referem à classificação tradicional de cláusulas relativas em restritivas e não-restritivas.

Diante dessas questões, e de considerar que as relações de dependência estabelecidas pela sintaxe podem ser alteradas pela estrutura informacional da fala, ou seja, de que a informação prosódica afeta a informação segmental na língua falada, este estudo propõe uma definição para a relativização clausal na fala espontânea a partir da Teoria da Língua em Ato - um quadro teórico-metodológico voltado para a investigação da fala -, e da observação de um minicorpus do português falado - o C-ORAL BRASIL -, os quais são apresentados a seguir.

\section{A TEORIA DA LÍNGUA EM ATO (L-ACT)}

A Teoria da Língua em Ato (L-AcT; CRESTI, 2000) estuda a fala espontânea, considerando a dimensão prosódica na sua estruturação. Por fala espontânea, compreende-se a fala que é executada ao mesmo tempo em que é planejada (NENCIONI, 1983). Logo, excluem-se as situações em que a fala é derivada de um texto escrito previamente elaborado, a exemplo de discursos lidos, peças teatrais, filmes, novelas etc.

A L-AcT é uma extensão da Teoria dos Atos de Fala (AUSTIN, 1962); no entanto, caracteriza-se como uma teoria corpus-driven. Para proceder à investigação da fala, haja vista a natureza transitória que marca a conjugação do meio (ondas sonoras) e do canal (o ar) de sua realização (RASO, 2013), a L-AcT constrói corpora considerando o critério semiortográfico para a transcrição dos textos orais (cf. RASO; MELLO, 2009, MELLO et al, 2012). Ou seja, já no processo de transcrição, esse arcabouço teórico adota uma

Carmo | Cláusulas relativas na fala espontânea:uma definição baseada na teoria da língua em ato 
codificação morfossintática para capturar características típicas da fala. Com essa metodologia, a L-AcT tenta evitar a interferência da língua escrita formal no processo de transcrição e capturar fenômenos em curso na língua.

Sendo assim, com base em critérios prosódicos, a L-AcT postula então o enunciado como a unidade de referência da fala, isto é, como a menor unidade linguística pragmaticamente autônoma que, dotada de força ilocucionária, corresponde a um ato de fala. Em outros termos, ao considerar os critérios prosódicos, a L-AcT rompe com a tradição dos estudos gramaticais que elege a sentença (CHOMSKY, 1970) ou a cláusula (CHAFE, 1988) como a unidade da língua. Afinal, tais postulados exigem que dentro dessas unidades haja um núcleo verbal. Entretanto, parte das ações linguísticas produzidas pelos falantes é realizada sem a presença de verbo, mas por chunks linguísticos que possuem valor comunicativo: fragmentos, interjeições, advérbios e alguns tipos de frases, tais como as nominais. Para efeito de demonstração, apresentam-se os exemplos de (1) a (6), retirados do minicorpus do C-ORAL BRASIL. Todos são enunciados, já que possuem autonomia pragmática e podem ser interpretados isoladamente, apesar dos diferentes conteúdos locutivos que veiculam:

(1) bfamcv01,213, eu acho que a gente deve chamar os $<$ times $>$ legais $/ /^{1}$

(2) bfamcv03,10, vou jogar na quatro //

(3) bfamcv03,9, < não > //

(4) bfamcv03,19, uhn //

(5) bfamcv03,51, < nts $>/ /$

(6) bfamcv04,416, pra todo mundo //

Tem-se de (1) a (6): um período composto por subordinação, um período simples, um advérbio, uma interjeição com valor interrogativo, um clique como manifestação de incômodo e um sintagma preposicional. Cada um desses enunciados apresenta um perfil prosódico particular. Logo, são identificados como atos de fala. Entretanto, o mesmo não acontece com a sequência a seguir:

$$
\text { bfamcv01,144,GIL, pra próxima taça / }
$$

Em (7), não se tem uma unidade pragmaticamente autônoma; isto é, essa sequência não é percebida como um enunciado. Na realidade, a sequência pra próxima taça é parte de um enunciado, reportado em (8), no qual a segunda parte a gente tem que também mandar um e-mail é percebida como uma ação linguística. Isso ocorre porque esta parte carrega o núcleo prosódico da ilocução, a ação da fala. Por isso, a última sequência é interpretada como pragmaticamente autônoma.

bfamcv01,144, pra próxima taça / a gente tem que também mandar um e-mail //

Assim, (8) é um enunciado que apresenta duas partes. Cada uma dessas partes possui um perfil prosódico diferente que determina a sua função dentro do enunciado. Ou seja, além de conferir autonomia pragmática ao conteúdo locutivo que constitui o enunciado nos termos de uma ilocução (ação linguística), a prosódia também é responsável por segmentar o enunciado no fluxo da fala.

Do ponto de vista da segmentação, a prosódia apresenta dois tipos de quebras: aquelas percebidas como conclusivas e que delimitam os enunciados - ou quebras terminais (“//" na transcrição); e aquelas percebidas como não conclusivas e que delimitam a estrutura interna dos enunciados em termos de unidades informacionais (UIs) - ou quebras não-terminais (“/” na transcrição). Os enunciados formados apenas por uma unidade informacional são chamados de enunciados simples. Estes são constituídos, obrigatoriamente, pela UI de Comentário, a qual é responsável pela interpretabilidade e autonomia pragmática do enunciado, uma vez que carrega a ilocução. Já os enunciados formados por mais de uma UI são chamados de enunciados complexos - istoé, o Comentário mais outra(s) unidade(s) informacional(is). Em (9) e (10), tem-se respectivamente um enunciado complexo formado por duas UIs (TOP-COM) e um enunciado simples formado por uma UI de Comentário (COM):

\footnotetext{
${ }^{1}$ Os enunciados do corpus C-ORAL-BRASIL possuem uma etiqueta de identificação que obedece ao seguinte formato: a sigla "bfamcv02" informa o seguinte - a língua $(\mathrm{b}=$ português brasileiro $)$, o contexto $(\mathrm{fam}=$ familiar/privado, pub = público $)$, a tipologia interacional $(\mathrm{cv}=\mathrm{conversação,} \mathrm{dl}=\mathrm{diálogo}, \mathrm{mn}=\mathrm{monólogo})$ e o número do texto em seguida. Os colchetes angulares indicam sobreposição de fala. As barras simples indicam quebras prosódicas não-terminais e as barras duplas indicam quebras prosódicas terminais.
} 
(9) bfamcv01,144, pra próxima taça /=TOP= a gente tem que também mandar um e-mail //=COM

(10) bfamcv01,8, < eles são piores do que o > Durepox //=COM

A L-AcT destaca que as quebras prosódicas do enunciado possuem duas dimensões concomitantes: uma prosódica e outra informacional. Na dimensão prosódica, a quebra terminal ou não-terminal é definida como unidade tonal. Na dimensão informacional, essa quebra é definida como unidade informacional. Como já adiantado, tais UIs estruturam internamente os enunciados que, no seu interior, são delimitados por quebras prosódicas não-terminais.

As unidades informacionais apresentam perfis prosódicos específicos, os quais possuem funções particulares dentro do enunciado e são definidas a partir de sua posição com relação ao COM - unidade responsável por veicular a ilocução. Tais unidades são determinadas a partir da observação da curva de $\mathrm{F}_{0}$ (frequência fundamental)2. Como movimentos voluntários, as UIs possuem saliência perceptual e carregam valores informacionais, em contraste com movimentos involuntários causados por fatores micromelódicos contextuais. Por sua natureza voluntária e intencional, as UIs são percebidas pelo falante. Diante disso, com base no modelo de fonologia perceptual do IPO (Institute for Perception Research), a L-AcT implementa a Information Patterning Theory que identifica os seguintes perfis prosódicos definidores da natureza das UIs:

(i) Raiz: define a ilocução e identifica apenas a unidade de COM.

(ii) Prefixo: precede unidades do tipo raiz e é típico do TOP.

(iii) Sufixo: segue unidades do tipo raiz e é típico das Apêndices de TOP e de COM.

(iv) Posfixo: pode preceder ou seguir unidades do tipo raiz, mas não pode ocorrer na posição inicial do enunciado, caso do Parentético.

No Quadro 1, tem-se as unidades informacionais segundo a L-AcT:

\begin{tabular}{|c|c|c|c|}
\hline & \multicolumn{3}{|r|}{ Quadro 1: Unidades informacionais } \\
\hline & Tipo & Tag & Função \\
\hline \multirow{5}{*}{ 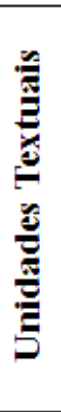 } & Comentário & $\mathrm{COM}$ & Veicula a força ilocucionária do enunciado. \\
\hline & Tópico & TOP & Estabelece o âmbito de aplicação da força ilocucionária. \\
\hline & $\begin{array}{l}\text { Apêndice de } \\
\text { comentário/ } \\
\text { tópico }\end{array}$ & $\mathrm{APC} / \mathrm{APT}$ & Integra textualmente a unidade da qual é apêndice. \\
\hline & Parentético & PAR & $\begin{array}{l}\text { Dá instruções sobre como deve ser interpretado o enunciado } \\
\text { ou parte dele. }\end{array}$ \\
\hline & $\begin{array}{l}\text { Introdutor } \\
\text { Locutivo }\end{array}$ & INT & $\begin{array}{l}\text { Sinaliza que o que segue têm nível hierárquico diferente } \\
\text { daquele da enunciação (geralmente, é uma metailocução). }\end{array}$ \\
\hline \multirow{6}{*}{ 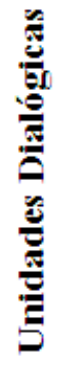 } & Alocutivo & ALL & Individualiza o interlocutor, marca coesão social. \\
\hline & Incipitário & INP & Sinaliza o começo do tumo ou do enunciado. \\
\hline & Expressivo & EXP & $\begin{array}{l}\text { Fomece suporte emotivo para o ato de fala, marca coesão } \\
\text { social. }\end{array}$ \\
\hline & $\begin{array}{l}\text { Conetor } \\
\text { Discursivo }\end{array}$ & DCT & Sinaliza continuidade de uma sequência com a anterior. \\
\hline & Fático & PHA & Sinaliza a abertura ou a manutenção do canal comunicativo. \\
\hline & Conativo & CNT & Induz o interlocutor a cumprir ou desistir de certa ação. \\
\hline
\end{tabular}

Fonte: Bossaglia (2015, p.312)

\footnotetext{
${ }^{2}$ Frequência fundamental: refere-se a uma medida do número de ciclos completos de vibração das cordas vocais por uma unidade de tempo (geralmente, o segundo) no momento da fala.
} 
Em resumo: as unidades textuais compõem o texto do enunciado (COM, TOP, APC, APT) ou são dirigidas à interpretação dele (INT, PAR); e as unidades dialógicas regulam a interação (ALL, CNT, DCT, EXP, INP, PHA). Estas últimas correspondem aos tradicionais marcadores discursivos. Há ainda outras unidades informacionais que apresentam certas particularidades, pois elas rompem o isomorfismo entre o padrão prosódico e o padrão informacional do enunciado, o que significa que há a atribuição de um valor pragmático-informacional a cada UIs dentro do enunciado, quais sejam: Comentário Múltiplo (CMM), Comentário Ligado (COB), e Unidade de Escansão (SCA).

CMMs e COBs, grosso modo, são sequências de dois ou mais comentários, cuja ilocução do enunciado, o qual compõe, resulta da padronização melódica do primeiro e da prosódia de continuidade do segundo. Ou seja, os CMMs apresentam padronização melódica e sua interpretação é holística, pois há uma relação lógica entre eles: causal, condicional, temporal etc. Esse padrão marca a lista, a comparação, por exemplo. Os COBs não apresentam padronização melódica, logo a interpretação não é holística. Eles formam estrofes (CRESTI, 2009), ou por outra, as ilocuçoes produzidas apresentam uma prosódia de continuidade, indicando que o discurso ainda não terminou e que este só termina quando se chega à última ilocução, que sinalizará a finalização do discurso. Tal padrão marca os textos monológicos. Os padrões de CMM e COB podem ser observados, respectivamente, em (11) e (12) abaixo:

(11) bfamcv01,66, mas a $<$ gente tenta $>$ fazer reunião $/=C M M=$ galera nũ $<$ comparece $>/ /=C M M$

(12) bfamcv01,94, a gente podia fazer a taça aqui $/=C O B \_r=$ todo mundo vai adorar $/=C O B \_r=e$ tal $/ /=C O M$

Já as SCAs ocorrem quando uma unidade informacional se realiza em mais de uma unidade tonal, seja em razão da quantidade de conteúdo locutivo produzido, seja por razões expressivas ou por imperícia do falante. As unidades escansionadas apresentam perfil neutro; somente a última sequência do padrão apresenta valor informacional, pois carrega o núcleo da ilocução. É importante salientar que a ocorrência de SCAs está restrita às unidades textuais e que há composicionalidade sintática dentro delas.

(13) bfamcv01,134, acho $<$ que a gente $>$ tem $/=S C A=$ que olhar direito $/ /=\mathrm{COM}$

Como se pode atestar, a L-AcT amplia o elenco das unidades da fala, no que se refere à sua estrutura informacional, antes restringido apenas às unidades de Tópico e Comentário. Essa forma de estruturar a fala em unidades informacionais é fundamental para a concepção de sintaxe da fala espontânea postulada pela a L-AcT e, por consequência, para a definição de relativização clausal, que será apresentada a seguir.

\subsection{A ARTICULAÇÃO SINTÁTICA E INFORMACIONAL NA L-ACT}

Para a L-AcT, a noção de sintaxe está articulada à estrutura prosódica. Dessa forma, a sintaxe stricto senso está restrita aos limites das unidades informacionais que se constituem como verdadeiras "ilhas sintático-semânticas". Assim, o output final do enunciado resulta da combinação dos vários elementos linguísticos, distribuídos nas unidades informacionais (UIs), que podem compor sentenças, sintagmas, frases e fragmentos diversos - chuncks linguísticos. Essa noção de combinação, que ocorre entre as "ilhas", é de natureza informacional, isto significa que é pragmaticamente orientada, e não pode ser confundida com a noção de composicionalidade sintática. Ou seja, as relações sintáticas de predicação, regência, modificação, subordinação e coordenação têm escopo apenas dentro de cada unidade informacional - ou ilha sintático-semântica. Para efeitos de demonstração, observa-se a relação entre as unidades informacionais de Tópico (TOP) e Comentário (COM) a seguir:

(14) bfamcv01,11, < porque o Durepox $>/=T O P=$ pelo menos jogava bola $/ /=C O M$

Em (14), tem-se duas unidades informacionais, TOP e COM, delimitadas por uma quebra prosódica não-terminal (“” na transcrição). Essas duas unidades compõem um enunciado, delimitado por uma quebra prosódica terminal ("//" na transcrição) no fluxo da fala. No contexto da L-AcT, a relação entre TOP-COM em (14) não se dá pela relação de predicação aparente, na qual o SN o Durepox em TOP seria o sujeito sintático do predicado pelo menos jogava bola em COM. De acordo com Cresti (2011), o TOP funcionaria como a representação linguística de uma proeminência pragmática/contextual que atua sobre a interpretação do

Fórum linguistic., Florianópolis, v.14,n.2,p.2061-2075, abr./jun.2017. 
conteúdo locutivo do COM. Essa relação entre TOP-COM é estabelecida pela prosódia ao marcar o papel informacional de cada unidade: o perfil prosódico de Prefixo do TOP não é o mesmo do perfil prosódico de Raiz do COM. Assim, o TOP funciona sempre como um anacoluto sintático e uma ilha semântica em relação ao COM. Em outras palavras, a relação sintática no padrão TOPCOM, nos termos tradicionais, só é possível se o comportamento da prosódia for desconsiderado.

Nessa perspectiva, a partir da noção de unidade informacional como ilha sintático-semântica, a L-AcT reconhece dois tipos de relação sintática na fala: a sintaxe linearizada e a sintaxe padronizada.

(i) Sintaxe linearizada: refere-se às estruturas de coordenação e subordinação que ocorrem dentro de uma única unidade informacional, cuja relação estabelecida é propriamente sintática. Em (15), tem-se todos os elementos de uma cláusula relativa na unidade informacional de COM; ou seja, '... N+QUE verbo finito... // UI', destacados em itálico:

(15) bfamdl01,176, cê nũ quer comprar um trenzinho que espirra pro seu banheiro não //=COM

(ii) Sintaxe padronizada: refere-se às estruturas de coordenação e subordinação que ocorrem distribuídas em mais de uma unidade informacional, cuja relação estabelecida é de natureza informacional e não propriamente sintática. Em (16), tem-se os elementos de uma cláusula relativa distribuídos entre duas unidades informacionais, COM-APC; ou seja, '... N / UI + QUE verbo finito... // UI', destacados em itálico:

(16) bfammn01,72, só até aí que eu sei $o$ caso $/=\mathrm{COM}=$ que ele me contou $/ /=\mathrm{APC}$

Diante disso, o conceito de cláusula relativa para fala espontânea, neste trabalho, leva em consideração, portanto, a estrutura informacional da fala nos termos defendidos pela L-AcT.

\subsection{CLÁUSULAS RELATIVAS NA FALA ESPONTÂNEA: UMA DEFINIÇÃO BASEADA NA L-ACT}

Uma cláusula relativa é definida tradicionalmente como uma subordinada que restringe a referência de um elemento nominal dentro de uma dada predicação (ROCHA LIMA, 1992; BECHARA, 2004; CUNHA, CINTRA, 2001; NEVES, 2000; PERINI, 2004). A maior parte das abordagens linguísticas identificam duas estratégias de cláusulas relativas: restritivas e não-restritivas. Apesar de ambas apresentarem configuração morfossintática semelhante '... N + QUE verbo finito...', semanticamente, no entanto, as restritivas delimitam o referente, e as não-restritivas não delimitam o referente ${ }^{3}$, apenas acrescentam uma informação sobre ele. Nesse contexto, somente as relativas restritivas encaixam-se dentro do conceito tradicional de cláusula relativa.

Diante de tal impasse, ou se alarga o conceito de relativa, ou se reconsidera o status de relativização das chamadas relativas nãorestritivas (CRISTOFARO, 2003; KEENAN, COMRIE, 1977). Este estudo opta pelo segundo posicionamento, tendo em vista: (i) a diferença cognitiva entre os dois tipos de relativa, já que uma delimita e a outra não; e (ii) a insuficiência do significante linguístico no que se refere às formas disponíveis, uma vez que estruturas morfossintáticas se repetem para expressar significados distintos, a exemplo de fenômenos como a homonímia (SALOMÃO, 1999). Além disso, para uma definição de relativização na fala espontânea, essa definição tradicional não leva em conta a estrutura informacional da fala. Sendo assim, esta investigação parte dos pressupostos da L-AcT acerca do funcionamento da sintaxe na fala (linearização e padronização) e da observação das cláusulas relativas no minicorpus C-ORAL-BRASIL para propor uma definição de relativização clausal.

Diante disso, os dados do minicorpus mostram que as cláusulas relativas ocorrem tanto em contextos de estrutura sintática linearizada quanto padronizada; entretanto, somente as restritivas exibem itens linguísticos que estabelecem o fenômeno da restrição. Nesses termos, o SN da cláusula evoca um background que estabelece a referência, ao passo que a cláusula relativa

\footnotetext{
${ }^{3} \mathrm{Na}$ escrita, são diferenciadas por sinais de pontuação e, na fala, por aquilo que a tradição identifica como "pausa prosódica”. Este conceito não pode ser confundido com quebra prosódica. Para mais detalhes, consultar O papel da pausa na segmentação prosódica de corpora de fala (RASO; MITTIMAN; OLIVEIRA, 2015).
} 
estabelece a especificação e a natureza dessa referência. Diante disso, nomeamos esse domínio estabelecido pelo SN de conjunto referência (geral), ao passo que a restrição operada pela cláusula relativa, de conjunto denotado ${ }^{4}$ (local). Essa operação é processada via inferência (LEVINSON, 2007) $)^{5}$. Para efeito de ilustração, apresenta-se a Figura I a seguir, que demonstra a relação entre conjunto referência $(\mathrm{SN})$ e conjunto denotado (cláusula relativa):

Figura I: Relação entre os conjuntos

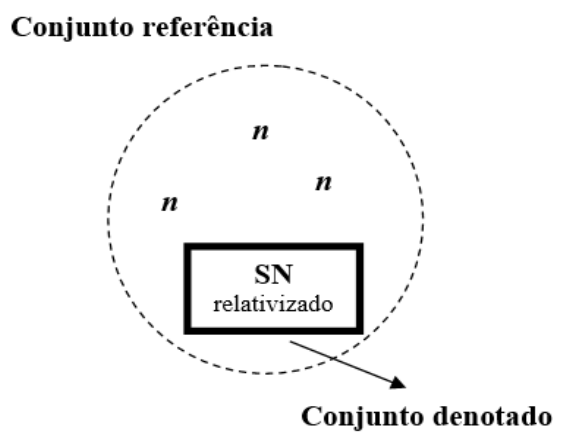

Nessa perspectiva, chegou-se à seguinte conclusão:

- $\quad$ A cláusula relativa apresenta a semântica de restrição somente quando delimita a interpretação de um referente (N) subespecificado nos termos de um conjunto denotado. Assim, o cálculo de sua condição de verdade vincula-se à existência de um conjunto referência, evocado em um nível semântico subjacente, no qual esse referente subespecificado está contido - assim como podem estar contidos outros elementos semelhantes. Do contrário, a semântica da cláusula é não-restritiva; logo, não fecha a interpretação de $\mathrm{N}$ nos termos de um conjunto denotado, tendo em vista a sua especificação. Assim, o cálculo de sua condição de verdade não está vinculado à existência de um conjunto referência.

Dessa forma, a interpretação restritiva da cláusula está vinculada aos seguintes parâmetros semântico-linguísticos, dado que estabelecem o conjunto referência subjacente:

(i) A interpretação distributiva associada aos quantificadores - sintagmas distributivos produzem a seguinte interpretação: "para cada um dos membros de um conjunto $(x, y, z \ldots)$, existem elementos distintos introduzidos por um quantificador associado às variáveis desse conjunto $(\mathrm{x}, \mathrm{y}, \mathrm{z} . .$.$) respectivamente".$

(ii)

(iii) A interpretação da pressuposição de existência da referência - sintagmas referenciais produzem a seguinte interpretação: "para cada N referencial, existe um referente potencial cujo valor de verdade ou falsidade pode ser confirmado".

Nesses termos, apenas as cláusulas restritivas podem ser consideradas instâncias de relativização, ao passo que as não-restritivas dizem respeito a outro fenômeno. Diante disso, passamos a nomear esta última de cláusulas informativas. Para identificar a diferença semântica entre cláusulas relativas e informativas, este estudo elabora o teste de relativização clausal, que consiste em verificar se a cláusula que apresenta a sintaxe da relativização, dentro de um enunciado simples ou complexo delimita a interpretação de um referente $(\mathrm{N})$ nos termos de um conjunto denotado ou não, haja vista o seu grau de especificação. Do contrário, não é relativa; tratase de cláusula informativa, que se assemelha sintaticamente à cláusula relativa, mas é semanticamente diferente. Para realizar esse

\footnotetext{
${ }^{4}$ As noções conjunto denotado e conjunto referente foram retiradas de Perini (1981) e de Lyons (1977).

${ }^{5}$ Isto é, o conteúdo implícito deduzido (conjunto referência) é acessado a partir de expressões linguísticas na superfície sintática através da cláusula relativa (conjunto denotado).
} 
teste, verifica-se a presença de expressões de quantificação e da pressuposição de existência da referência estabelecedoras do conjunto referência. Para efeitos de demonstração, seguem os exemplos de (17) a (20)

(17) bfammn02,51, papai foi o irmão que mais deu apoio a ele //=COM

Referente: o irmão

Conjunto denotado: irmão que mais deu apoio a ele

Conjunto de referência: conjunto de irmãos

Tipo de cláusula: relativa linearizada em COM

A cláusula relativa que mais deu apoio a ele estabelece o conjunto de referência irmãos, no qual os possíveis itens contidos apresentam traços distintos do conjunto denotado irmão que mais deu apoio a ele por meio do quantificador adverbial mais. Logo, a cláusula irmão que mais deu apoio a ele é verdadeira, pois existe um conjunto de irmãos.

(18) bfamdl01,176 cê nũ quer comprar um trenzinho que espirra pro seu banheiro não // COM

Referente: um trenzinho

Conjunto denotado: trenzinho que espirra

Conjunto de referência: conjunto de trenzinhos ${ }^{7}$ para o banheiro

Tipo de cláusula: relativa linearizada em COM

A cláusula relativa que espirra estabelece o conjunto de referência trenzinhos para o banheiro, no qual os possíveis itens contidos apresentam traços distintos do conjunto denotado trenzinho que espirra, por meio da pressuposição de existência. Logo, a cláusula trenzinho que espirra é verdadeira, pois existe um conjunto de trenzinhos para o banheiro.

(19) bfammn06,33, e esse caso $/=\mathrm{TOP}=$ que acontecia $/=\mathrm{APT}=$ marcava muito $/ /=\mathrm{COM}$

Referente: esse caso

Conjunto denotado: $\varnothing$

Conjunto de referência: Ø

Tipo de cláusula: cláusula informativa padronizada em TOP-APT

A cláusula que acontecia não estabelece o conjunto de referência (outros casos?) subjacente. Dessa forma, não há a restrição do conjunto denotado e a oposição entre os conjuntos. Logo, a cláusula que acontecia apenas acrescenta uma informação sobre um referente especificado, esse caso. Assim, seu conteúdo não precisa ser calculado em termos de condição de verdade.

(20) bfamdl02,73, que eu dou um exemplo de porta /=TOP=que é excelente //=COM

Referente: Um exemplo de porta

Conjunto denotado: $\varnothing$

Conjunto de referência: $\varnothing$

Tipo de cláusula: cláusula informativa padronizada em TOP-COM

A cláusula que é excelente não estabelece o conjunto de referência (exemplos de portas?) subjacente. Dessa forma, não há a restrição do conjunto denotado e a oposição entre os conjuntos. Logo, a cláusula que é excelente apenas acrescenta uma informação sobre um referente especificado, um exemplo de porta. Assim, seu conteúdo não precisa ser calculado em termos de condição de verdade.

\footnotetext{
${ }^{6}$ Para as cláusulas que não estabelecerem o conjunto denotado e o conjunto de referência, marca-se Ø (conjunto vazio) no teste.

${ }^{7}$ Refere-se a desinfetantes de vasos sanitários, os quais podem se apresentar em forma de pedra, gel ou líquido.
} 
Para demonstrar a diferença sintática, semântica e informacional desses dois tipos de cláusulas na fala espontânea do PB, cláusula relativa linearizada e cláusula informativa padronizada, a formalização ${ }^{8}$ é realizada nos seguintes termos:

(i) Cláusula relativa linearizada

Em termos sintáticos, é um tipo de cláusula subordinada (B) que funciona como termo adjunto de um SN (x), ao qual está conectada por meio de um pronome relativo (QUE), inserido no seu conteúdo locutivo. No enunciado, os elementos da cláusula relativa podem ocorrer contidos sintaticamente numa cláusula matriz - $(\mathrm{SN}+[\mathrm{QUE}+\mathrm{B}]) \subset \mathrm{A} / /, \log \mathrm{B}(\subset$ ) A //; ou isolados desta - (SN + [QUE+B] $\varnothing / /)$. Semanticamente, a função da cláusula relativa é restringir/delimitar o $\mathrm{N}$ (x) dentro de um conjunto referência subjacente, possivelmente composto por outros elementos semelhantes. Em termos prosódicos, o $\mathrm{N}$ antecedente e a cláusula relativa ocorrem linearizados sintaticamente dentro de uma mesma unidade informacional num enunciado simples ou complexo:

Diagrama I: Cláusula relativa linearizada

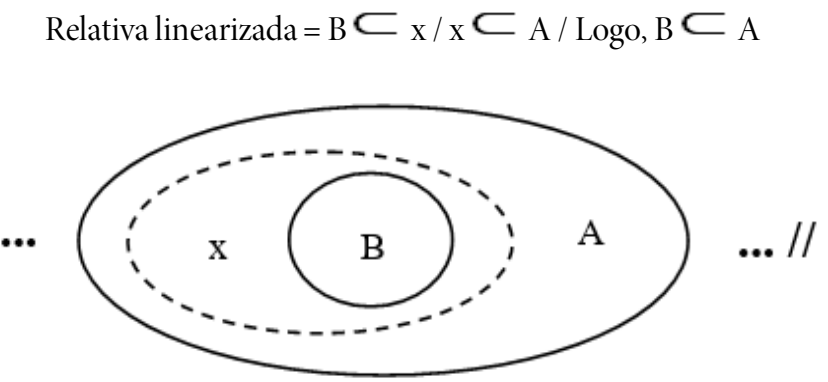

Abaixo, seguem exemplos de cláusulas relativas linearizadas retirados do minicorpus do C-ORAL BRASIL, conforme a descrição proposta:

(21) bfamdl04,18, tem [creme $\left.\left[q u e_{\text {ProRel }}+\text { nũ dá com o cabelo não }\right]_{\mathrm{CRel}}\right]_{\mathrm{SN}} / / \mathrm{COM}$

(22) bfamdl01,177, [trenzim $\left.[\text { que ProRel }+ \text { espirra }]_{\mathrm{CRe}}\right]_{\mathrm{SN}} / / \mathrm{COM}$

Em (21), o SN creme que nũ dá com o cabelo não contém uma cláusula relativa restritiva que nũ dá com o cabelo não como um termo sintático adjunto. Como o $\mathrm{N}$ creme é subespecificado, pois possui um alcance potencial de referentes no mundo (creme que dá versus creme que não dá com o cabelo), a restrição da cláusula relativa incide apenas sobre o elemento do conjunto de referência, que corresponde ao creme que não dá com o cabelo, ou seja, o conjunto denotado. Em termos sintáticos, esse SN funciona como argumento da cláusula matriz, tem um creme... Prosodicamente, os itens da cláusula relativa estão linearizados sintaticamente no interior de uma mesma unidade informacional, o COM, dentro do enunciado simples.

Em (22), o SN trenzim que espirra ${ }^{9}$ contém, como um termo sintático adjunto, uma cláusula relativa restritiva que espirra. Como o $\mathrm{N}$ trenzim é subespecificado, possui um alcance potencial de referentes no mundo (trenzinho que espirra, que não espirra, que derrete, que fica pendurado - ou conjunto referência), a restrição da cláusula relativa incide apenas sobre o elemento do conjunto que espirra - ou seja, o conjunto denotado. Em termos sintáticos, ela funciona isolada, isto é, sem uma cláusula matriz, contudo possui autonomia informacional, é uma ilocução. Prosodicamente, os itens da cláusula relativa restritiva estão linearizados sintaticamente dentro de uma mesma unidade informacional, o COM, dentro do enunciado simples.

(ii) Cláusula informativa padronizada

\footnotetext{
${ }^{8}$ A formalização diagramática das cláusulas relativas apresentada aqui começou a ser desenvolvida em trabalho anterior. Para mais detalhes, cf. Carmo e Mello (2016, no prelo).

${ }^{9} \mathrm{O}$ termo trenzinho/trenzim é usado para se referir a desinfetante sanitário.
} 
Em termos sintáticos, é um tipo de cláusula apositiva (B) que está em intersecção semântica ( $\cap$ com o $\mathrm{N}$ antecedente (x) da cláusula matriz (A), através do pronome relativo (QUE) inserido no seu conteúdo locutivo. Este pronome permite recuperar, anaforicamente, o conteúdo semântico de N. Entretanto, B não está contido $(\not \subset)$ em A como um termo sintático. No enunciado, os elementos da cláusula informativa podem ocorrer distribuídos, apostos a uma cláusula matriz - (SN / [QUE+ B] $) \subset \mathrm{A} / / \Rightarrow \mathrm{B}(\not \subset)$ A //) ou isolados desta - (SN / [QUE+ B]) Ø//). Semanticamente, B apenas adiciona uma informação sobre o $\mathrm{N}(\subset)$ A. Em termos prosódicos, $\mathrm{o} N$ antecedente e a cláusula informativa ocorrem padronizados em diferentes unidades informacionais dentro de um enunciado complexo.

Diagrama II: Cláusula informativa padronizada

Informativa padronizada $=\mathrm{B}(\bigcap \mathrm{A}=\{\mathrm{x}\} /$ Entretanto, $\mathrm{B} \not \subset \mathrm{A}$

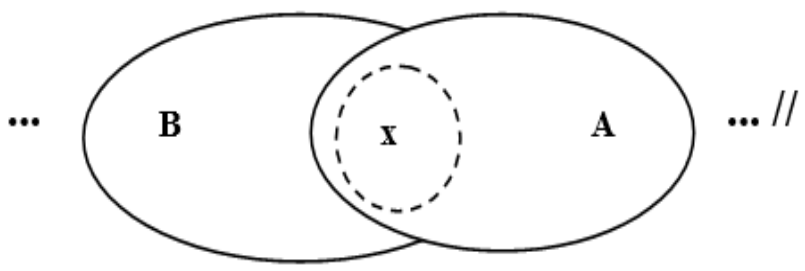

Abaixo, seguem exemplos de cláusulas informativas retirados do minicorpus do C-ORAL BRASIL, conforme a descrição proposta:

(23) bfamcv01,56, tem $[\text { o SESC }]_{\mathrm{SN}} / \mathrm{COB}[\text { que é bom pa caramba }]_{\mathrm{CRel}} / / \mathrm{COM}$

(24) bfamdl02,30, [um cuidado $]_{\mathrm{SN}} /$ que cês têm que tomar $]_{\mathrm{CRel}} / / \mathrm{COM}$

Em (23), a cláusula informativa padronizada que é bom pa caramba está numa relação de interseção semântica com a cláusula matriz tem o SESC, por meio do pronome relativo que, o qual recupera anaforicamente o conteúdo semântico do SN antecedente inserido na cláusula matriz: o SESC. Entretanto, a cláusula informativa não está contida no SN foco como um termo sintático adjunto. Ela é um termo aposto da cláusula matriz. A cláusula informativa não delimita o SN, o qual já está especificado, ou seja, não estabelece o conjunto referência. Diante disso, sua função é apenas adicionar uma informação sobre o SN da cláusula matriz. Em termos prosódicos, a cláusula informativa ocorre na unidade informacional de COM, e o SN antecedente ocorre na unidade informacional de $\mathrm{COB}$, dentro de um enunciado complexo. Portanto, seus elementos estão padronizados sintaticamente em unidades informacionais diferentes.

Em (24), a cláusula informativa que cês têm que tomar está numa relação de interseção semântica com o SN referente um cuidado, por meio do pronome relativo que, o qual recupera anaforicamente o conteúdo semântico de N. Entretanto, a cláusula informativa padronizada não está contida no SN foco como um termo sintático adjunto. Ela é um termo aposto. Assim, a cláusula informativa padronizada não delimita o SN, sua função é apenas adicionar uma informação sobre ele, ou seja, não estabelece o conjunto referência. Sintaticamente, a cláusula informativa funciona isolada, isto é, sem uma cláusula matriz; contudo, possui autonomia informacional - é uma ilocução. Em termos prosódicos, a cláusula informativa ocorre na unidade informacional de COM e o SN antecedente na unidade informacional de TOP dentro de um enunciado complexo. Por isso, estão padronizados sintaticamente em unidades informacionais diferentes.

Para a análise dos dados, este estudo segue a metodologia descrita a seguir.

\section{METODOLOGIA}

Este estudo adota os pressupostos metodológicos da Linguística de Corpus (MELLO, 2014). Sendo assim, será utilizada uma amostra balanceada do corpus C-ORAL-BRASIL, a qual será chamada de minicorpus.

Carmo | Cláusulas relativas na fala espontânea:uma definição baseada na teoria da língua em ato 
O minicorpus deste estudo integra o C-ORAL-BRASIL (RASO; MELLO, 2012), corpus balanceado do português falado, especificamente da diatopia mineira (Belo Horizonte e região metropolitana). Cada sessão do corpus contém áudio, seção de metadados, transcrição e alinhamento de texto-som. O minicorpus do C-ORAL-BRASIL também está organizado assim; porém, ele possui a anotação da estrutura informacional de cada ilocução, a qual respeita as quebras prosódicas terminais e não-terminais, definidoras do enunciado e de sua estrutura interna, requisito precípuo da Information Patterning Theory (CRESTI, 2000; MONEGLIA; CRESTI, 2006). Em termos de tamanho, o minicorpus apresenta as seguintes proporções: vinte textos, 31318 palavras e 5512 sequências terminais (enunciados). Ele segue a mesma arquitetura do C-ORAL-BRASIL, ou seja, quanto ao contexto da interação, está dividido em dois domínios: familiar/privado e público. Cada um desses domínios está dividido em três tipologias de interação: conversações, diálogos e monólogos (RASO, 2012).

O minicorpus do C-ORAL-BRASIL está disponível na plataforma de busca online DP - IPIC ${ }^{10}$ (PANUNZI; GREGORI, 2011). Tal plataforma foi desenvolvida pelo LABLITA (Laboratório de Linguística da Università Degli Studi di Firenze). Nela, também estão depositados tanto a seção informal do corpus do italiano falado C-ORAL-ROM ${ }^{11}$ como o seu minicorpus.

\section{CLÁUSULAS RELATIVAS NO MINICORPUS DO C-ORAL-BRASIL: RESULTADOS}

Para o levantamento das cláusulas relativas, foi utilizada a plataforma DP - IPIC. A partir de sua interface de pesquisa, buscou-se, no minicorpus do PB, os enunciados que continham o subordinante que. Do total dos 5512 enunciados do minicorpus, 1821 apresentavam tal subordinante. Entretanto, só em 148 ocorrências o que funcionava como pronome relativo. Tais dados foram classificados e distribuídos em planilhas eletrônicas, conforme a estrutura sintática informacional: linearizada e padronizada. Dessa forma, dois grupos foram constituídos: $\left(1^{\circ}\right)$ cláusulas relativas que ocorrem sintaticamente linearizadas dentro de uma única unidade informacional; e $\left(2^{\circ}\right)$ cláusulas informativas que ocorrem sintaticamente distribuídas em mais de uma unidade informacional. Assim, chegou-se aos números expostos na Tabela 1 a seguir:

\section{Tabela 1:}

Total Distribuição das cláusulas segundo a sintaxe informacional no minicorpus

123 Cláusulas relativas linearizadas

25 Cláusulas informativas padronizadas

\section{Ocorrências}

Contudo, tanto cláusulas linearizadas quanto as padronizadas podem ocorrer acompanhadas ou isoladas de uma cláusula matriz dentro do enunciado. Dessa maneira, têm-se os seguintes contextos:

\footnotetext{
${ }^{10}$ Information Structure Database <http://ablita.dit.unifi.it/app/dbipic/>.

${ }^{11}$ O C-ORAL-ROM é um corpus multilíngue das quatro principais línguas românicas europeias: italiano, português europeu, francês e espanhol. Desenvolvido a partir da parceria entre quatro universidades europeias, é coordenado pelo LABLITA e é financiado pela União Europeia. Para maiores informações sobre o CORAL-ROM, cf. Cresti e Moneglia (2005).
} 
- $\quad$ Contexto sintático complexo: a cláusula subordinada (relativa ou informativa) ocorre com uma cláusula matriz como um de seus argumentos. Esta cláusula matriz, como conteúdo locutivo, está distribuída dentro de um enunciado simples ou complexo: “... $\mathrm{N}[\mathrm{QUE}+$ verbo finito...]ClSub+ Cl. Matriz....

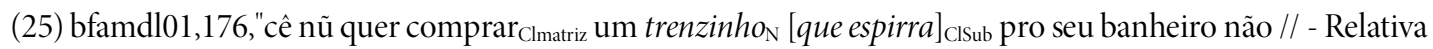

(26) bfamcv01,56,"tem Clmatriz $_{\text {o }} S E S C_{\mathrm{N}}[\text { que é bom pa caramba }]_{\text {Clsub }} / /$ - Informativa

- $\quad$ Contexto sintático simples: a cláusula subordinada (relativa ou informativa) não ocorre com uma cláusula matriz. Ela funciona sozinha como conteúdo locutivo dentro de um enunciado simples ou complexo. Doravante, SN relativizado: “... N [QUE + verbo finito...] ClSub - Ø ....

(27) bfamdl01,177, trenzim $_{\mathrm{N}}[\text { que espirra }]_{\mathrm{ClSub}} / /$ - Relativa

(28) bfamdl02, 30,um cuidado / [que cês têm que tomar] Clsubl // - Informativa

Abaixo, encontram-se os números seguidos de ocorrências que correspondem aos padrões informacionais e sintáticos encontrados.

Tabela 2:

Total Distribuição das cláusulas relativas conforme o contexto sintático-informacional

97 Linearizadas em contexto sintático complexo.

26 Linearizadas em contexto sintático simples.

21 Padronizadas em contexto sintático complexo

04 Padronizadas em contexto sintático simples

\section{Ocorrências}

Como se pode observar na Tabela 2, foram encontradas 97 ocorrências de cláusulas relativas linearizadas e 21 ocorrências de cláusulas relativas padronizadas com a estrutura sintática complexa, isto é, acompanhadas da cláusula matriz “... N [QUE + verbo finito...]ClSub + Cl. Matriz...”. No entanto, foram encontradas também trinta ocorrências de cláusulas relativas isoladas que funcionam informacionalmente. Dessas, 26 são linearizadas e quatro padronizadas, cuja estrutura sintática ocorre em contexto simples, isto é, sem a cláusula matriz: “... N [QUE + verbo finito...] ClSub - Ø ....

Quanto à semântica das cláusulas relativas encontradas no minicorpus do C-ORAL BRASIL, aplicou-se o teste da relativização clausal e o resultado encontrado segue na tabela 3:

Tabela 3

Total Distribuição das cláusulas quanto aos tipos semânticos

123 Cláusulas relativas linearizadas

25 Cláusulas informativas padronizadas

148 Ocorrências 
A Tabela 3 mostra que as cláusulas relativas ocorrem linearizadas sintaticamente dentro do enunciado, englobando tanto cláusulas que ocorrem em contexto sintático complexo quanto em contexto sintático simples. Essas cláusulas correspondem às relativas, dado que apresentam a semântica de restrição. Ao passo que as cláusulas informativas ocorrem padronizadas sintaticamente dentro do enunciado, envolvendo tanto cláusulas que ocorrem em contexto sintático complexo quanto em contexto sintático simples. Essas cláusulas não correspondem às relativas, dado que não apresentam a semântica de restrição, embora, como já salientado, apresentem estrutura sintática semelhante.

Tal achado corrobora o postulado de Cresti (2014) sobre as cláusulas relativas do italiano: a relativa restritiva corresponde a uma ilha sintático-semântica, ocorrendo linearizada dentro de uma única unidade informacional no enunciado, que pode ser simples ou complexo. Já a relativa não-restritiva corresponde à combinação de pelo menos duas ilhas sintático-semânticas, ocorrendo padronizada, ou seja, distribuída em diferentes unidades informacionais, cada uma cumprindo a sua função informacional no enunciado complexo.

\section{CONSIDERAÇÕES FINAIS}

Este estudo apresentou a análise das cláusulas relativas extraídas do minicorpus do C-ORAL-BRASIL. Os dados mostraram que, do total de 5512 enunciados do minicorpus, 148 apresentam estrutura sintática de cláusula relativa. Dessas 148 ocorrências, 123 cláusulas relativas ocorrem linearizadas dentro de uma única unidade informacional num enunciado simples ou complexo, ao passo que 25 dessas cláusulas ocorrem padronizadas em mais de uma unidade informacional dentro de enunciados complexos. Contudo, das 123 cláusulas relativas linearizadas, 97 ocorrem em contexto sintático complexo (SN [QUE + verbo finito] + Cl. Matriz), enquanto 26 ocorrem em contexto sintático simples (SN [QUE + verbo finito] Ø) nos enunciados. No caso das 25 cláusulas relativas padronizadas, 21 ocorrem em padrão sintático complexo, enquanto quatro ocorrem em contexto sintático simples.

Para resolver a semântica das relativas, tradicionalmente identificadas em relativas restritivas e relativas não-restritivas, este estudo propõe o teste da relativização clausal, que verifica se a cláusula estabelece um conjunto referência subjacente para a sua interpretação, tendo em vista o grau de especificação do referente. O resultado da aplicação do teste possibilitou verificar que apenas as relativas linearizadas sintaticamente estabelecem um conjunto referência subjacente, tendo em vista a presença de quantificadores e/ou da pressuposição de existência. Contrariamente, as cláusulas padronizadas sintaticamente não estabelecem esse conjunto subjacente para a sua interpretação. Diante desse achado, assume-se que, na fala espontânea, somente as cláusulas relativas linearizadas, identificadas com a semântica de restrição, são instâncias de relativização.

As relativas padronizadas, a despeito de sua estrutura sintática semelhante, não são relativas, já que possuem semântica e estrutura informacional distintas das relativas verdadeiras. Diante disso, passa-se a nomeá-las de cláusulas informativas. Os resultados apresentados aqui corroboram os estudos linguísticos que advogam que a relativização clausal só englobam as tradicionais relativas restritivas.

\section{REFERÊNCIAS}

BECHARA, E. Moderna gramática portuguesa. 37ed. Rio de Janeiro: Lucerna, 2004.

BOSSAGLIA, G. Orientação pragmática da sintaxe na fala: uma análise corpus-based da subordinação completiva e adverbial no português do Brasil. Domínios de Lingu@gem, v. 9, n. 5 (dez. 2015), p. 309-335, 2015. Disponível em: <http://www.seer.ufu.br/index.php/dominiosdelinguagem/article/view/29246> Acesso em: 15 de jul. de 2016.

CARMO, C; MELLO, H. Cláusulas relativas na fala espontânea do português do Brasil: um estudo exploratório baseado no corpus C-Oral-Brasil. Signum: Estudos da Linguagem, v. 19, n. 2, 2016.

Disponível em: < http://www.uel.br/revistas/uel/index.php/signum/article/view/25097 > Acesso em: jan.2016.

Fórum linguistic., Florianópolis, v.14,n.2, p.2061-2075, abr./jun.2017 
CINTRA, L.; CUNHA, C. Nova gramática do português contemporâneo. 3.ed. Rio de Janeiro: Nova Fronteira, 2001.

CRESTI, E. Corpus di Italiano parlato. Firenze: Accademia della Crusca, 2000.

CRESTI, E. Syntactic properties of spontaneous speech in the language into act theory: data on italian complements and relative clauses. In: RASO, T.; MELLO, H. (Org.). Spoken corpora and linguistic studies: Problems and perspectives. 1ed. Amsterdam/Philadelphia: John Benjamins, 2014. p. 365-410.

CRESTI, E; MONEGLIA, M. (Ed.). C-ORAL-ROM: integrated reference corpora for spoken romance languages. Amsterdam/Philadelphia: John Benjamins, 2005.

CRISTOFARO, S. Subordination. Oxford: University Press, 2003.

KEENAN, E. Relative clauses. In: SHOPEN, T. (Ed.) Language Typology and Syntactic Description. Cambridge: University Press, 1985, v.2. p. 206-236.

KEENAN, E. L.; COMRIE, B. Noun Phrase Accessibility and Universal Grammar. Linguistic Inquiry, n. 8, p. 63-99, 1977.

HART, J; COLLIER, R; COHEN, A. A Perceptual Study on Intonation: An Experimental Approach to Speech Melody. Cambridge: CUP, 1990.

KATO, M. A. et al. As construções-Q no português brasileiro falado: perguntas, clivadas e relativas. In: KOCH, Ingedore V.G (Org.). Gramática do Português falado VI. 2.ed.Campinas, SP: Editora da UNICAMP, 2002. p. 309-374.

LYONS, J. Semantics 1. Cambridge: Cambridge University Press, 1977.

MELLO, H. What Corpus Linguistics can offer Contact Linguistics: The C-oral-Brasil corpus experience. PAPIA, São Paulo, v.24, n.2, p. 407-427, Jul/Dez 2014. Disponível em: < http://revistas.fflch.usp.br/papia/article/view/2204> Acessado em: 15 de jul.2016.

NEGRÃO, Esmeralda V. Forma Lógica e quantificação. In: MULLER, A. l., NEGRÃO, E.V.;

NEVES, M. H.M. Gramática de usos do português. São Paulo: 2000. p. 71-95

PANUNZI, A; GREGORI, L. DB-IPIC: an XML database for the representation of information structure in spoken language. In: MELLO, H.; PANUNZI, A.; RASO, T. (Ed.). Pragmatics and Prosody: Illocution, Modality, Attitude, Information Patterning and Speech Annotation. Firenze: Firenze University Press, 2012. p. 133-150.

Carmo | Cláusulas relativas na fala espontânea:uma definição baseada na teoria da língua em ato 
PERINI, M. A. Gramática descritiva do português. 4.ed. São Paulo: 2004.

PERINI, M. A. Um aspecto da interpretação do tópico em português. Publicação do Curso de Letras do Centro de Ciências Humanas e Letras das Faculdades Integradas de Uberaba. Série Estudos - 7, Uberaba, MG, 1981.

RASO, T. Fala e escrita: meio, canal, consequências pragmáticas e linguísticas. Domínios de Lingu@Gem, v. 7, p. 12-46, 2013. Disponível em: <http://www.seer.ufu.br/index.php/dominiosdelinguagem/article/view/23730> Acesso em: 20 jul. 2016.

RASO, T; MELLO, H.. (Org). C-ORAL-BRASIL I: Corpus de referência do português brasileiro falado informal. Belo Horizonte: Editora UFMG, 2012.

SALOMÃO, M.M.M. A questão da construção do sentido e a revisão da agenda dos estudos da linguagem. Veredas, v.2, Juiz de Fora: EDUFJF, 1999. 